\title{
Endoscopic hook knife cutting before balloon dilatation of a severe anastomotic stricture after rectal cancer resection
}

Anastomotic stricture associated with suture failure develops in $5 \%-10 \%$ of patients after resection of rectal cancer [1]. Direct digital dilatation or transrectal surgical treatment is possible if the anastomosis is located in the lower rectum. Endoscopic balloon dilatation is the best method for all the remaining patients in whom these procedures for the lower rectum cannot be done [2]. However, double stapling of the rectal anastomosis may induce intractable and severe re-stenosis, so a procedure that includes endoscopic incision with a papillotomy knife has been reported $[3,4]$.

In this patient, severe anastomotic stricture was identified before stoma closure at 1 year after the creation of a right transverse colon loop colostomy for anastomotic leakage following resection of advanced rectal cancer. Balloon dilatation had already been performed once. Because this was a male patient with a narrow pelvis and a high body mass index, laparotomy/re-anastomosis was considered to be very difficult after the improvement of pelvic floor peritonitis, and endoscopic treatment was considered to be the best option. Follow-up gastrografin enema showed severe re-stenosis at the rectal anastomosis, although the passage of gastrografin was very good ( $\bullet$ Fig. 1 a). Colonoscopy revealed old inflammatory granulation tissue in the rectum with a pin-hole-like lumen in the center (॰ Fig. 1 b).

It was therefore decided to perform balloon dilatation after making an incision at the severe stenosis with a hook knife (KD620LR disposable high-frequency knife; Olympus Medical Systems Corp., Tokyo, Japan), which is generally used for endoscopic submucosal dissection. This highfrequency knife has a hooked part that can be freely rotated through 360 degrees. The length of the knife is $4.5 \mathrm{~mm}$, the hook length (depth) is $1.3 \mathrm{~mm}$, and the largest outer diameter is $2.6 \mathrm{~mm}$. Operability in the direction of the long axis of the rectum is easy, unlike the conventional papillotomy knife or pre-cutting needle knife, and the operator can directly feel with the right hand the sensation of incising the rectal wall at the stenosis to a depth

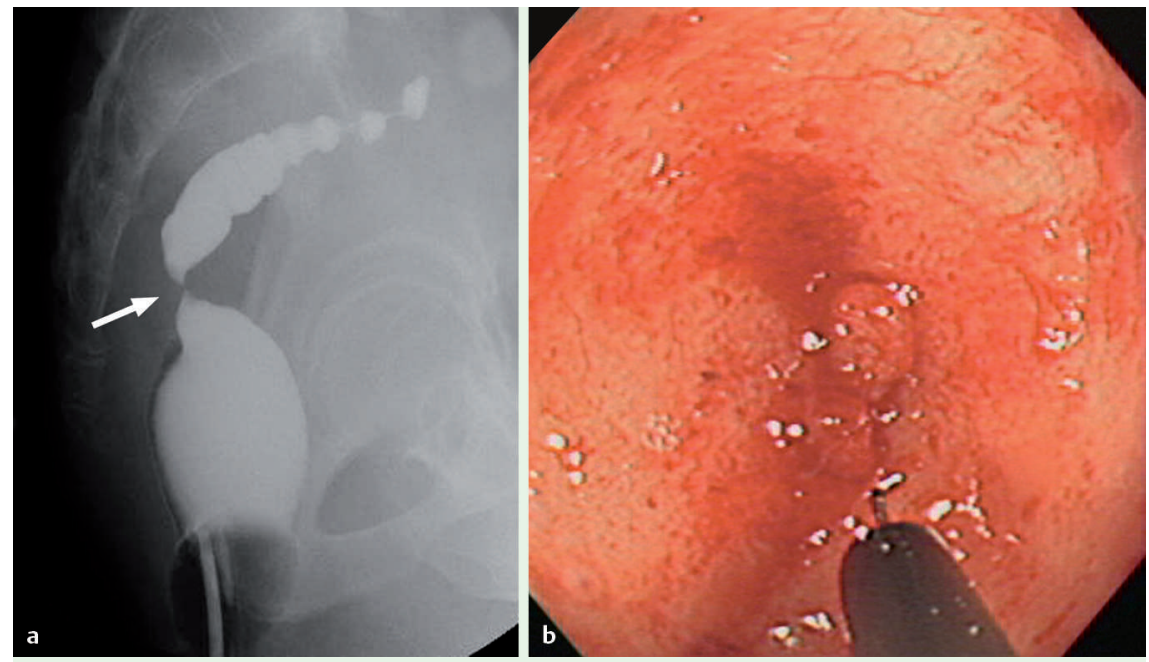

Fig. 1 Follow-up gastrografin enema shows severe re-stenosis at the rectal anastomosis, although passage of gastrografin to the anal side is good. b Colonoscopy shows that the rectum contains old inflammatory granulation tissue with a slight pin-hole-like lumen in the center.
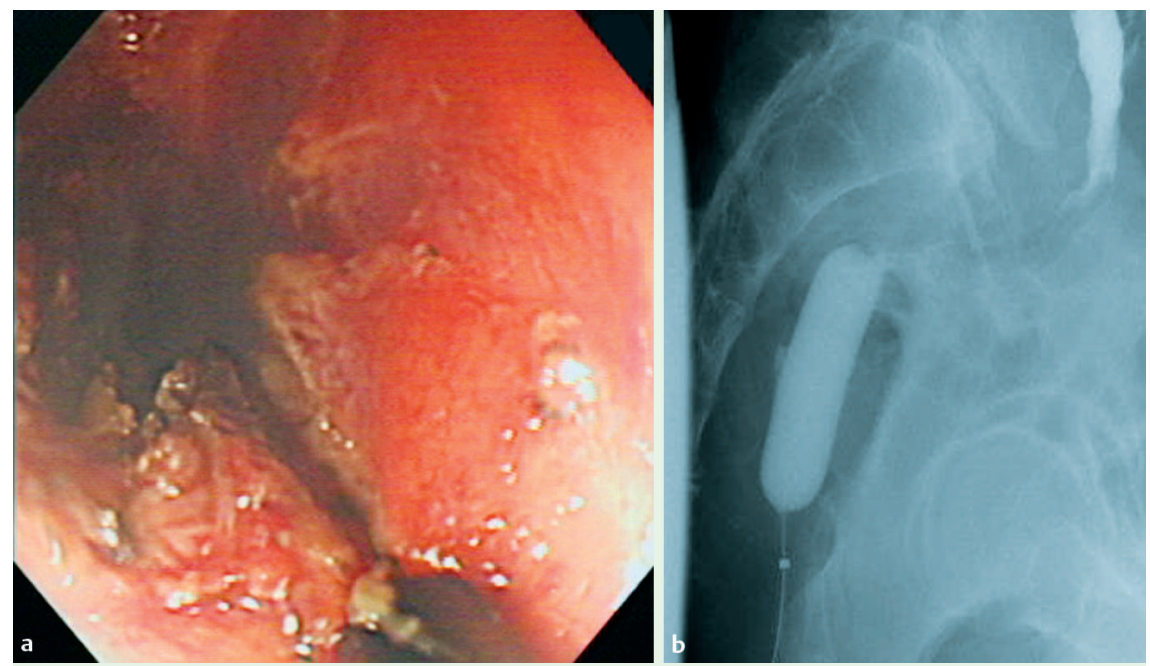

Fig. 2 This high-frequency knife is a hook knife and the hooked part can be freely rotated through 360 degrees. The length of the knife is $4.5 \mathrm{~mm}$, the hook is $1.3 \mathrm{~mm}$ long, and its largest outer diameter is $2.6 \mathrm{~mm}$. a Operability in the direction of the long axis of the rectum is very good. $\mathbf{b}$ Balloon dilatation was performed after incising the stenosis by safely pulling the colonoscope from the oral side to the anal side without causing perforation.

of $1.3 \mathrm{~mm}$ while monitoring the performance of electrocautery ( Fig. 2 a) $[4,5]$. Accordingly, balloon dilatation was performed at the maximum pressure after incising the stenosis at a total of eight sites. The colonoscope was pulled back from the oral to the anal side without creating complications after confirming the absence of leakage/perforation by colonog- raphy ( Fig. 2 b). As a result, a balloon $20 \mathrm{~mm}$ in diameter could be easily passed through the anastomosis ( $\bullet$ Fig. $\mathbf{3} \mathbf{a}, \mathbf{b}$ ). Stoma closure is now scheduled because re-stenosis has not been observed by 1 month after the procedure.

Endoscopy_UCTN_Code_TTT_1AQ_2AF 

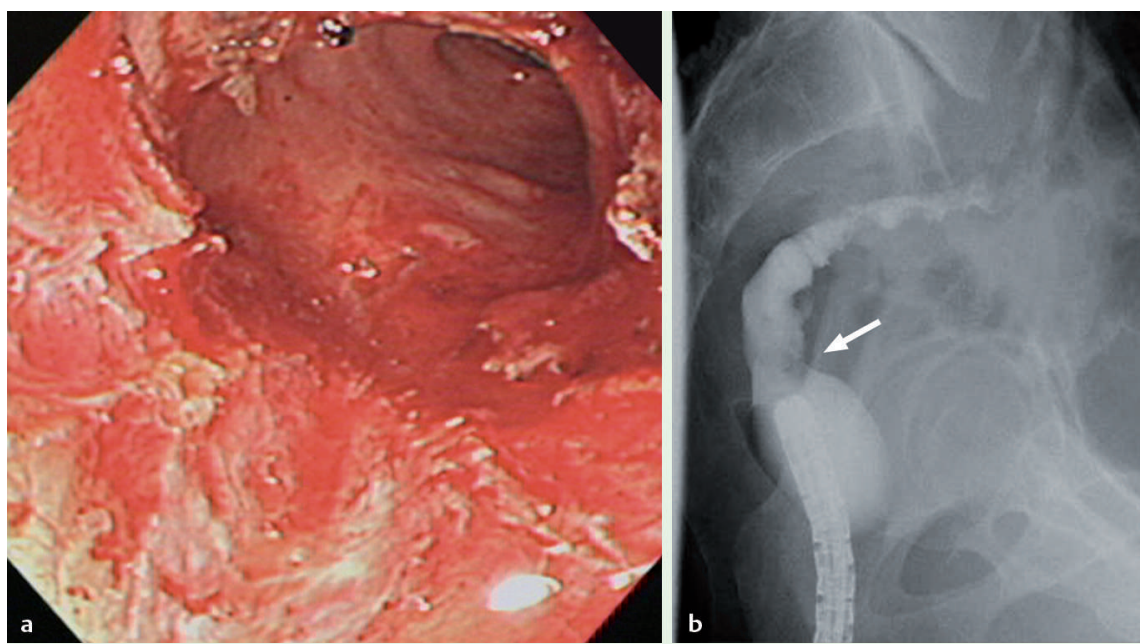

Fig. 3 a, b A balloon of $20 \mathrm{~mm}$ in diameter was easily passed through the anastomasis and no re-stenosis has been observed at 1 month after treatment.

\section{Mukai' ${ }^{1}$, K. Kishima ${ }^{1}$, S. lizuka ${ }^{1}$,}

H. Fukumitsu' ${ }^{1}$, M. Fukasawa ${ }^{1}$,

N. Yazawa' ${ }^{1}$, T. Tajima ${ }^{1}$, M. Nakamura ${ }^{2}$, H. Makuuchi ${ }^{3}$

${ }^{1}$ Department of Surgery, Tokai University Hachioji Hospital, Tokyo, Japan

2 Department of Pathology, Tokai University School of Medicine, Bohseidai, Isehara, Kanagawa, Japan

${ }^{3}$ Tokai University School of Medicine, Department of Surgery, Bohseidai, Isehara, Kanagawa, Japan

\section{References}

1 Luchtefeld MA, Milsom JW, Senagore A et al. Colorectal anastomotic stenosis: results of a survey of the ASCRS membership. Dis Colon Rectum 1989; 32: 733-736

2 Venkatesh KS, Ramanujam PS, McGee S et al. Hydrostatic balloon dilatation of benign colonic anastomotic strictures. Dis Colon Rectum 1992; 35: 789-791

3 Hagiwara A, Sakakura C, Shirasu M et al. Sigmoidfiberscopic incision plus balloon dilatation for anastomotic cicatricial stricture after anterior resection of the rectum. World J Surg 1999; 23: 717-720
4 Chiku T, Sano W, Shinnmura $K$ et al. Three cases of endoscopic incision and dilatation with papillotome for the treatment of stenotic colorectal anastomsis (in Japanese with English abstract). Gastroenterol Endoscopy 2002; 44: 1960-1964

5 Mukai M, Iwase H, Himeno S et al. Novel approach to colorectal endoscopic mucosal resection using a three channel outer tube and multiple forceps: an experimental assessment. Endoscopy 2001; 33: 253-256

Bibliography

DOI $10.1055 / \mathrm{s}-0029-1214776$

Endoscopy 2009; 41: E193-E194

(c) Georg Thieme Verlag KG Stuttgart · New York . ISSN 0013-726X

Corresponding author

M. Mukai, MD, PhD

Department of Surgery

Tokai University Hachioji Hospital

Ishikawa-cho 1838

Hachioji-city

Tokyo 1920032

Japan

Fax: +81-42-6391112

mukai.masaya@hachioji-hosp.tokai.ac.jp 